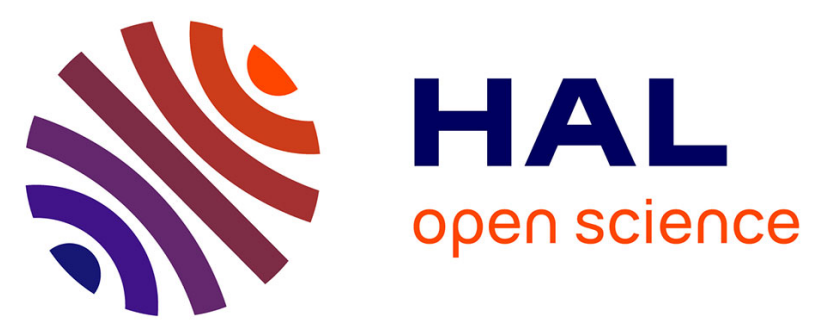

\title{
2014 French guidelines for hepatitis B and C screening. A combined targeted and mass testing strategy of chronic viruses namely HBV, HCV and HIV
}

Julie Bottero, Cécile Brouard, Françoise Roudot-Thoraval, Sylvie Deuffic-Burban, Philippe Hofliger, Armand Abergel, Johan Volant, Daniel

Dhumeaux, Yazdan Yazdanpanah

\section{To cite this version:}

Julie Bottero, Cécile Brouard, Françoise Roudot-Thoraval, Sylvie Deuffic-Burban, Philippe Hofliger, et al.. 2014 French guidelines for hepatitis B and C screening.A combined targeted and mass testing strategy of chronic viruses namely HBV, HCV and HIV. Liver International, 2016, 10.1111/liv.13135 . hal-01299138

\section{HAL Id: hal-01299138 \\ https://hal.sorbonne-universite.fr/hal-01299138}

Submitted on 7 Apr 2016

HAL is a multi-disciplinary open access archive for the deposit and dissemination of scientific research documents, whether they are published or not. The documents may come from teaching and research institutions in France or abroad, or from public or private research centers.
L'archive ouverte pluridisciplinaire HAL, est destinée au dépôt et à la diffusion de documents scientifiques de niveau recherche, publiés ou non, émanant des établissements d'enseignement et de recherche français ou étrangers, des laboratoires publics ou privés. 
2014 French guidelines for hepatitis B and C screening.

A combined targeted and mass testing strategy of chronic viruses namely HBV, HCV and HIV

Julie Bottero ${ }^{1,2}$, Cécile Brouard ${ }^{3}$, Françoise Roudot-Thoraval ${ }^{4}$, Sylvie Deuffic-Burban ${ }^{5,6}$, Philippe Hofliger ${ }^{7}$, Armand Abergel $^{8}$, Johan Volant $^{9}$, Daniel Dhumeaux ${ }^{10}$, Yazdan Yazdanpanah ${ }^{5,11}$ for the Viral Hepatitis Testing Experts group

1 Sorbonne Universités, UPMC Univ Paris 06, INSERM, Institut Pierre Louis d'épidémiologie et de Santé Publique (IPLESP UMRS 1136), F75012, Paris, France

2. AP-HP, Hôpital St Antoine, Service de Maladies Infectieuses, F-75012 Paris, France

3. Institut de veille sanitaire, Département des Maladies Infectieuses, Saint-Maurice, France

4. AP-HP, Groupe Hospitalier Henri Mondor, Service de Santé Publique, Université ParisEst-Créteil, Créteil, France

5. INSERM, IAME, UMR 1137, F-75018 Paris, France; Univ Paris Diderot, Sorbonne Paris Cité, F-75018 Paris, France

6. Inserm, LIRIC-UMR995, F-59000 Lille, France; Univ Lille, F-59000 Lille, France

7. Université de Nice Sophia Antipolis, Département d'Enseignement et de Recherche en Médecine Générale, Nice, France

8. CHU de Clermont-Ferrand - Hôpital d'Estaing, Service d'hépato-gastro-entérologie, Clermont-Ferrand, France

9. Fédération Sos hépatites, F-75020, Paris, France

10. AP-HP, Groupe Hospitalier Henri Mondor, Service d'Hépato-Gastro-Entérologie, Université Paris-Est-Créteil, Créteil, France

11. AP-HP, Hôpital Bichat-Claude Bernard, Service de Maladies Infectieuses, F-75018 Paris, France.

\section{Viral Hepatitis Testing Experts group:}

Armand Abergel, Jean-Pierre Aubert, Julie Bottero, François Bourdillon, Nathalie Boyer, Cécile Brouard, Stéphane Chevaliez, Sylvie Deuffic-Burban, Juliette Foucher, Arnaud Gautier, Philippe Hofliger, Jean-Marie Le Gall, Denis Ouzan, Henri Partouche, Francoise Roudot-Thoraval, Caroline Semaille, Nathalie Spenatto, Johann Volant, Yazdan 
Yazdanpanah

\section{Corresponding author:}

Julie Bottero, MD, PhD

Service de Maladies Infectieuses - Hôpital St Antoine.

184, rue du faubourg St Antoine

75012 Paris, FRANCE

Tel: + 33171970424

Fax: +33149282595

E-mail: julie.bottero@aphp.fr

Electronic word count: 4953 words

Number of figures and tables: 3 Figures and 2 Tables

\section{Abbreviations :}

AFEF : Association Française pour l'Etude du Foie

ANRS: Agence Nationale de Recherche contre le SIDA et les Hépatites virales CDC: Centers for Disease Control and Prevention

HBs Ag: Hepatitis B surface Antigen

HBV: Hepatitis B Virus

HCC: Hepatocellular carcinoma

HCV: Hepatitis C virus

HIV: Human immunodeficiency Virus

GPs: General Practitioners

POC: Point-Of-Care 
No conflict of interest.

No Financial Support

\section{KEY POINTS}

- Worldwide, a minority of individuals infected with hepatitis B or C is aware of its status. Given the limits of a targeted strategy and given that the majority of unaware individuals in France are men, without any specific age-trend for HCV, France established new recommendations for $\mathrm{HBV}$ and $\mathrm{HCV}$ testing:

- HBV, HCV and HIV tests should be quasi-systematically combined

- Targeted screening should be strengthened using rapid point-of-care tests and large information campaigns

- A routine testing for these 3 viruses should be offered to all pregnant women and, at least once, to men of 18 to 60 . 


\section{ABSTRACT (249 words)}

\section{Backround \& Aims}

Worldwide and, to a lesser extent, in France, a minority of individuals infected with hepatitis $\mathrm{B}(\mathrm{HBV})$ and $\mathrm{C}(\mathrm{HCV})$ is aware of its status. Given the current availability of highly effective anti-HBV and anti-HCV agents, the high rate of undiagnosed people, associated with individual and community prejudices (liver disease worsening, persistence of a hidden transmission reservoir, and medico-economic burden of delayed care), is unacceptable.

\section{Methods}

On the occasion of the first French general report on viral hepatitis, new recommendations for HBV and HCV testing were issued. We aim to introduce the new French strategy for HBV and HCV screening, and to describe the underlying epidemiological data.

\section{Results}

These recommendations comprise various items. First, the screening of chronic viruses namely HBV, HCV and HIV should be quasi-systematically combined. Second, the targeted screening of groups at risk of viral exposure must be strengthened. Third, routine testing for each of these three viruses should be offered at least once to men of 18 to 60 years old who had never been tested. In parallel, in pregnant women, in addition to HIV-HBV screening currently recommended, HCV testing should be routinely performed during the first trimester of pregnancy.

In order to best achieve the target populations, community initiatives that propose testing actions should be encouraged, particularly those including rapid point-of-care tests.

\section{Conclusions}

Overall, these recommendations aim to define a comprehensive testing strategy for chronic viral infections, emphasizing both targeted screening and mass screening and considering jointly HBV, HCV and HIV.

\section{KEY WORDS}

Hepatitis B; Hepatitis C; Testing; Screening 


\section{TEXT}

\section{Introduction}

In France, as in other developed countries, testing for infection with hepatitis B (HBV) and C virus $(\mathrm{HCV})$ is a major public health issue. With the arrival of direct-acting antivirals that allow a viral cure in $90 \%$ of patients [1], HCV infection is currently undergoing a therapeutic revolution which lead to hope, if associated with a significant improvement of HCVawareness among infected individuals, HCV eradication. For HBV, current treatments allow viral control in the majority of patients, with little resistance and good tolerance. For these two infections, treatments and viral replication termination are associated with a reduced risk of developing cirrhosis and hepatocellular carcinoma (HCC) [2, $\underline{3}]$.

In parallel to therapeutic advances, screening tools get diversified with the development of HCV and HBV point-of-care (POC) rapid tests, which enable a broader variety of screening strategies, including testing for people outside the structures care.

In addition to individual benefit, early detection generates a collective benefit associated to the reduction of the infection transmission risk, but also, by limiting progression to cirrhosis or $\mathrm{HCC}$, long-term reduction of the cost of care. For HBV, testing also precise the immune status and thus incite to vaccinate unvaccinated persons at risk of exposure.

Compared to these benefits, the rate of under-detection of viral hepatitis observed in most of the developed countries is no longer acceptable. Therefore, for HCV diagnosis, some countries such as the United States or Canada recommend now population screening for certain age groups, regardless of risk factors, in addition to targeted screening $[\underline{4}, \underline{5}]$. However, recommendations for HBV testing have not recently been amended. Despite a slightly more favourable position than other European countries or the United States [5-8], France faces also under-detection with about half of the 500,000 people with HBV or HCV who are unaware of their viral status [9] .

In this context, and taking the opportunity of the first French report on the care of people infected with HCV or HBV [10], new recommendations for testing were issued. The purpose of this article is first to review past testing strategies for HCV and HBV, to describe what were their results and their impact, and based on this to introduce the new French strategy for hepatitis $B$ and $C$ screening.

\section{Materials and methods}

\section{Expert Panel}


In spring 2013, as part of the preparation of the report on the management of people infected with HCV or HBV, a group of 19 "Testing experts" was established and validated by the National Research Agency against AIDS and Viral Hepatitis (ANRS) and the French Association for the Study of the Liver (AFEF). This group comprised general practitioners, hepatologists, infectious disease specialists, virologists, epidemiologists and representatives of patient groups. A list of questions was set up to guide the group on the evaluation of the status of the viral hepatitis screening and the development of recommendations (Table 1) [11]. Questions were dealing with the description of previous testing strategies, their impact and in particular data on characteristics of HBV and HCV epidemics, and their limits in terms of organisation namely tools and actors. All the data on these themes were considered, whether or not published. The texts related to each of these themes were written in subworking groups and submitted for review to all group members. The final document was forwarded to the committee for report validation and summary.

\section{Data sources}

\section{Previous screening guidelines}

Current recommendations were, for HCV, those issued by the National Agency for Accreditation and Health Evaluation in 2001 [12]. For HBV, testing of HBs antigen (HBsAg) is mandatory in pregnant women in the $6^{\text {th }}$ month of pregnancy, and in the context of blood donations [13]. In addition previous guidelines [14] recommend screening focused on people with at least one risk exposure from those listed in Table 2.

\section{Sociodemographic characteristics of overall infected individuals}

Sociodemographic characteristics of HBV or HCV infected individuals and those of them unaware of their status were provided by the 2004 national seroprevalence survey [ 9 ] that was updated for HCV in 2014 [15]. Methods used to conduct this survey have been previously described $[\underline{9}, 15]$. In summary, the 2004 seroprevalence survey was a crosssectional survey conducted among a random sample of 18-80 years old residents of mainland France. The survey protocol was approved by a national ethical review board (CCPPRB, October 25, 2002, no. 02-035). Selected individuals received an invitation for a free medical checkup. Overall, 14,416 people were included after written informed consent and received HBV and HCV antibody screening. Data were collected for demographic characteristics, potential exposure to HBV or HCV, prior testing and infection awareness. For HCV, the 2014 estimates were determined using an epidemiologic model taking into account mortality, HCV incidence and diagnosis rates and applied to undiagnosed 
chronically-infected HCV cases aged 18 to 80 in 2004. Analyses were performed for each year from 2004 to 2014, for each gender and age-group. Multiple data sources were compiled to feed the model. To take into account uncertainties of the model parameters and estimate plausible interval around the estimated number of undiagnosed HCV persons in 2014, several scenarios were studied.

No updated estimation was determined for HBV epidemiological data.

\section{Characteristics of infected individuals at diagnosis}

The Hepatology Reference Centers surveillance network based on university hepatology wards in hospitals throughout France which report, for every HBV or HCV newly referred patients, circumstances of testing, at risk exposures co morbidities and severity of the liver disease [16, 17].

\section{HBV and HCV testing activity}

To evaluate HBV and HCV activity The "LaboHep" national survey [18, 19] were carried out in France from a random sample of 1,412 laboratories in 2010 and 1,504 laboratories in 2013, taking into account the sampling design and the laboratories' activity.

\section{Barriers to HBV and HCV testing}

Published and grey data on testing organization and in particular actors and tools was reviewed in order to address current barriers to screening implementation and to refine the HBV and HCV testing strategy. We mostly focused on the French literature.

\section{$\underline{\text { Results }}$}

\section{Characteristics of overall infected individuals}

In 2004, the prevalence of chronic infection with HCV (HCV RNA) and HBV (HBsAg) among the general adult population in metropolitan France was estimated at $0.53 \%$ (95\% Cl: 0.40 to $0.70)$ and $0.65 \%$ (95\% Cl: 0.45 - 0.93), accounting for 232,196 (95\% Cl: 167,869 - 296,523) and 280,821 people $(95 \% \mathrm{Cl}: 179,730-381,913)$, respectively [9]. HCV RNA prevalence was slightly different in men $(0.45 \%$; $95 \% \mathrm{Cl}: 0.28$ - 0.71) and in women $(0.62 \%$; $95 \% \mathrm{Cl}$ : $0.40-0.95)$ and tended to increase with age (Figure 1). Conversely, HBV prevalence was higher among men $(1.1 \%, \mathrm{Cl} 0.73-1.67)$ than women $(0.21 \% \mathrm{Cl}: 0.10-0.47)$ and tended to decrease with age (Figure 1).

Among infected individuals, only $57 \%(95 \% \mathrm{Cl} 41-71)$ of people with chronic hepatitis $\mathrm{C}$ and $45 \%$ (95\% Cl: $23-69)$ of HBsAg positive persons [9] were, in 2004 , aware of their status. Of 
note, for HCV the overall proportion of persons aware of their HCV seropositivity may have evolved from $24 \%$ in 1994 to $57 \%$ in 2004 [20] and to $65 \%$ in 2014 [ㄷ, 15$]$.

For both viruses, based on 2004 data, the proportion of infected people aware of their status differs across age groups (Figure 2).

For HCV, among the 232,196 people chronically infected in 2004, 100,868 (95\% Cl 58,534$143,202)$ were unaware of their status, including 55,385 women $(95 \% \mathrm{Cl}, 20,162-90,608)$ (55\%) and 45,483 men (95\% Cl, 17,986-72,980) (45\%). Figure 3 illustrates distribution by age and gender of undiagnosed individuals. Apart from the high proportion of undiagnosed patients among women aged over 60 years of age, who are in 2016 more than 70 years of age, there is no age trend in the proportion of undiagnosed hepatitis $C$ patients and especially among men. The update of these estimates for 2014 [15] showed that the rate of men aged 18 to 59 among undiagnosed people for hepatitis C was higher in 2014 (45\%) than in 2004 (27\%). Conversely, the rate of undiagnosed women aged over 60 years has declined. For hepatitis B, a large majority (81\%; 95\% Cl: 87,988-221,923) of the 154,956 undiagnosed people were, in 2004, men, aged 18 to 59 years for $90 \%$ of them. In HBVundiagnosed women, nearly two-third of the 29,079 [95\% Cl $775-57,384]$ women was aged 18 to 39 (Figure 3).

Overall, the comparison of distributions by age and sex of HBV-undiagnosed and HCVundiagnosed people showed that $55 \%$ of all of these undiagnosed people in 2004 are men aged 18 to 59 years [15].

The rate of infected people aware of their status also depends on the risk exposure. For $\mathrm{HCV}$, rates have been estimated between $73 \%$ and $91 \%$ among people who inject drugs at least once in life [21], 51\% among those transfused before 1992, and 35\% among those who have no history of drug use or transfusion before 1992 [9]. For HBV, it ranges from 57\% among those born in low endemic area to $16 \%$ for those born in area moderately or highly endemic for HBV [9].

\section{Characteristics of infected individuals at diagnosis}

A significant proportion of patients diagnosed for hepatitis C or B at the end of 2000 and followed in liver diseases reference centres were at late stages of disease : $13 \%$ of men and $10 \%$ of women newly diagnosed for hepatitis C had advanced disease (cirrhosis or hepatocellular carcinoma) [16]. For HBV, it reached $13 \%$ of men and $3 \%$ of women [17]. Of note among the overall diagnosed patients, less than a quarter were detected thanks to risk factors targeting. For most of them, testing was performed incidentally during an overall health assessment [22]. 


\section{HBV and HCV testing activity}

Testing activity rose steadily since the early 2000 s $[\underline{18}, \underline{22}]$ and was estimated at 55 antiHCV tests per 1000 and 58 HBsAg tests per 1000 inhabitants in 2013 versus 53 anti-HCV tests per 1000 and 53 HBsAg tests per 1000 inhabitants in 2010 [18, 19] The estimated positivity rates of anti-HCV and HBsAg screening test performed in France in 2013 were $0.9 \%$ for anti-HCV and $0.8 \%$ for HBsAg [19], i.e., not much better to the estimated positivity test prevalence in the general population (respectively $0.84 \%$ and $0.65 \%$ for anti-HCV and HBsAg) [9].

\section{Current barriers to screening implementation}

Some barriers to screening implementation are related to the widespread lack of knowledge about viral hepatitis and their exposure risk factors among the general population [23, 24] and among those at risk [25]. In turn, some physicians are insufficiently aware of the weight of the various risk factors [26], or are sometimes struggling to explore the potential exposure of their patient. Several studies have shown inadequate testing practices. According to a survey of a random sample of 2,083 general practitioners (GPs) in France, HBV testing is not systematically proposed to people at risk of HBV infection: $38.6 \%$ of GPs said they routinely propose screening to people from highly endemic countries, $55.9 \%$ to those with sexual risk behaviours and $61.8 \%$ to the household of HBsAg-positive patients [27]. Similarly, only $59.5 \%$ of surveyed physicians reported routine HCV testing proposal to people having got transfused before 1992. However, the HCV and HBV testing are more frequently proposed to intravenous drug addicts (76.6\% and $73.1 \%$, respectively) [27]. Two other surveys showed that only 34 to $40 \%$ of at-risk patients had HCV screening test [28, 29]. The main barriers to testing are the physician unawareness of the patient exposure to a risk situation [24], and his/her ignorance of some risk factors as such [26, 28, 29], in a context where people at risk sometimes deny their own risk exposure, which further complicates the targeted testing. Moreover the difficulty of identifying people at risk, the complexity of the prevention exercise for physicians involved in many missions must also be pointed out. Therefore, it rules out a monothematic approach, but enables to take every opportunity to propose a hepatitis screening test, combined with the detection of other sexually transmitted infections where appropriate. In addition, previous experience of low compliance to the routine HIV screening recommendations issued in France in 2008 [30] shows the need for a clearly understandable and pragmatic strategy. Indeed, the recommendation to screen for HIV at least once the general population aged 15 to 70 years regardless of their risk exposure was rarely applied [31]. The low implementation of this testing recommendation is partly due to a lack of 
perceptible benefit by the doctor, given the small number of expected positive tests despite an expected impact of this recommendation at the societal level [32].

\section{Testing access/ Point-of-care tests}

The development of HBV and HCV POC tests enables community initiatives to propose screening interventions for these infections, along with HIV. As for the POC HIV tests used for many years $[\underline{30}, \underline{33}]$, these tests require minimal equipment and a puncture capillary whole blood from the fingertip or a simple cravicular liquid sampling. Easy to perform, including by non-medical personnel, the result is obtained in less than 30 minutes. Rapid tests performances have been supported by several studies [34-37]. To date, the use of POC tests for HCV has been validated by the CDC in the US [11] and the High Authority of Health in France [38]. However POC tests for HBV screening have not yet been formally validated, and are not used in current practice in Western countries. Although POC tests have a slightly lower sensitivity than classical serological tests and require a specific organization to allow traceability of results, several studies attest to the importance of these practice tests to promote access to screening for target audiences [39-41].

\section{Discussion}

Epidemiologic data of HCV and HBV-infected patients presented here illustrate, that under current testing strategies, France faces under-detection of people infected with HCV or HBV. One strategy to increase the rate of diagnosed people is to complement the targeted screening based on risk exposures by a population-based screening, likewise the recent recommendations issued by the United States and Canada (i.e., people born between 1945 and 1965 for the former, and those born between 1945 and 1975 for the latter) $[4,5]$. However, in the French epidemiological context showing no specific age trend for overall undiagnosed population but also the limits of target approach and the necessity to promote a pragmatic, easily expandable and pluri-thematic testing strategy, a similar birth-cohort HBVHCV testing strategy would not be appropriate. In contrast, based on these data, in addition to targeted screening on risk exposures, a strategy targeting men would be more pragmatic (males accounted for $67 \%$ of undiagnosed HCV and HBV in 2004 [42]). Moreover, in this population, because of common demographic characteristics, a combined HIV and HBVHCV population-based testing strategy (chronic viral infections) would be more acceptable to health professionals and probably cost-effective; males accounted for $70 \%$ of undiagnosed HIV in 2010 [43]. 
Screening should be promoted in various medical environments such as during a medical consultation (general practitioner, or specialists), in sexually-transmitted diseases clinics, during inpatients visits, in prisons, but also during interventions organised within communities thanks to new POC tests. Indeed these settings host at-risk populations such as migrants, and people who inject drugs, who do not necessarily attend health care settings and who feel more comfortable to report difficulties or unsafe practices within the associative framework.

During pregnancy, due to the possible need for HBV treatment at the last trimester, combined to the delay in specialized management initiation, it appeared desirable to advance the mandatory HBV testing (previously recommended during the last trimester) just after the initial pregnancy assessment, along with other serological tests. For HCV, given the possible risk of mother-to-child transmission (about $5 \%$ [44]), and the recent availability of highly effective antiviral agents with few adverse events (and although their safety during pregnancy need to be demonstrated), the routine testing among pregnant women, previously not recommended, is now considered and could be performed in combination with the HIV and HBV testing during the 1st trimester of pregnancy.

In summary, based on the inventory carried out, the main recommendations issued by the Group and included in the first French report on the care of people infected with HCV or HBV published in May 2014 are the followings [10]:

1) Combine the testing for the chronic viruses (namely, HBV, HCV and HIV), given the epidemiological similarities, and in order to simplify screening indications and favour empowerment by all medical and associative. In this perspective, the development of combined HIV-HBV-HCV rapid tests should be encouraged;

2) Continue targeted screening strategy for hepatitis $B$ and $C$, according to the risk exposure, as currently recommended. It should be supported by large-scale information of the general population and information of general practitioners. Importantly, HCV testing should be renewed regularly in some populations at risk (such as injectable drug users).

3) Set up a population-based testing for HBV, HCV and HIV, by offering a screening test of the following populations at least once in their life: (1) Men aged 18 to 59 years, mainly following a proposal from their general practitioner, and (2) Pregnant women at the first prenatal visit.

4) Encourage the use of rapid POC tests for screening populations who do not attend traditional medical facilities. The training of the non-health professional staff who will offer 
these tests is essential for the screening acceptance and the subsequent appropriate treatment;

Of note, in addition to testing recommendations, it is important to promote interventions that allow a better linkage-to care of infected individuals. The importance of linkage to care, in line with screening strategies improvement has been recently illustrated in particular in France $[41, \underline{45}, \underline{46}$. To evaluate the proportion of infected patients aware of their infection, national epidemiological studies should be regularly conducted and should, likewise in HIV, provide data to estimate HCV/ HBV cascade of-care.

Overall, 2014 French HBV-HCV-testing recommendations aimed to clarify the respective indications of testing for hepatitis $B$ and hepatitis $C$, and, above all, to define a global strategy emphasizing both targeted screening and mass testing, and considering jointly the three chronic viral infections, HBV, HCV and HIV. 


\section{References}

1. Pawlotsky JM. New hepatitis C therapies: the toolbox, strategies, and challenges. Gastroenterology 2014,146:1176-1192.

2. European Association for Study of Liver. EASL clinical practice guidelines: Management of chronic hepatitis B virus infection. J Hepatol 2012,57:167-185.

3. van der Meer AJ, Veldt BJ, Feld JJ, Wedemeyer H, Dufour JF, Lammert F, et al. Association between sustained virological response and all-cause mortality among patients with chronic hepatitis $\mathrm{C}$ and advanced hepatic fibrosis. JAMA 2012,308:2584-2593.

4. Grebely J, Bilodeau M, Feld JJ, Bruneau J, Fischer B, Raven JF, et al. The Second Canadian Symposium on hepatitis C virus: a call to action. Can J Gastroenterol 2013,27:627-632.

5. Smith BD, Morgan RL, Beckett GA, Falck-Ytter Y, Holtzman D, Teo CG, et al. Recommendations for the identification of chronic hepatitis $C$ virus infection among persons born during 1945-1965. MMWR Recomm Rep 2012,61:1-32.

6. Deuffic-Burban S, Deltenre P, Buti M, Stroffolini T, Parkes J, Muhlberger N, et al. Predicted effects of treatment for HCV infection vary among European countries. Gastroenterology 2012,143:974-985 e914.

7. Hatzakis A, Wait S, Bruix J, Buti M, Carballo M, Cavaleri M, et al. The state of hepatitis B and C in Europe: report from the hepatitis B and C summit conference*. J Viral Hepat 2011,18 Suppl 1:1-16.

8. Weinbaum CM, Williams I, Mast EE, Wang SA, Finelli L, Wasley A, et al. Recommendations for identification and public health management of persons with chronic hepatitis B virus infection. MMWR Recomm Rep 2008,57:1-20.

9. Meffre C, Le Strat Y, Delarocque-Astagneau E, Dubois F, Antona D, Lemasson JM, et al. Prevalence of hepatitis B and hepatitis C virus infections in France in 2004: social factors are important predictors after adjusting for known risk factors. $J$ Med Virol 2010,82:546-555.

10. Dhumeaux D. [Management of people infected by HBV or HCV. Recommendations report.]. www.sante.gouv.fr/pdf/Rapport Prise en_charge_Hépatites_2014.pdf 2014.

11. Smith BD, Morgan RL, Beckett GA, Falck-Ytter Y, Holtzman D, Ward JW. Hepatitis $C$ virus testing of persons born during 1945-1965: recommendations from the Centers for Disease Control and Prevention. Ann Intern Med 2012,157:817-822.

12. Agence nationale d'accréditation et d'évaluation en santé (ANAES). [Hepatitis C screening - populations to be screened and screening procedures. Recommendations of the Experts Committee set up by the ANAES]. http://www.has-sante.fr/portail/upload/docs/application/pdf/hepatite.pdf 2001.

13. Haute Autorité de Santé (HAS). Stratégies de dépistage biologique des hépatites virales B et C. http://www.has-sante.fr/portail/jcms/c 1050355/fr/strategies-dedepistage-biologique-des-hepatites-virales-b-et-c 2011.

14. Ministère de la Santé et des Sports. [2015 vaccinations calendar and vaccinations recommendations.] http://www.sante.gouv.fr/IMG/pdf/Calendrier vaccinal 2015.pdf 2015.

15. Brouard C, Le Strat Y, Larsen C, Jauffret-Roustide M, Lot F, Pillonel J. The undiagnosed chronically-infected HCV population in france. Implications for expanded testing recommendations in 2014. PLoS One 2015,10:e0126920. 
16. Brouard C, Delarocque-Astagneau E, Meffre C, Pioche C, Silvain C, Larsen C, et al. Trends of hepatitis $\mathrm{C}$ screening in France through Rena-VHC and hepatology reference centres surveillance systems, 2000-2007. . Bull Epidemiol Hebd 2009,20/21:199-204.

17. Brouard C, Pioche C, Le Vu S, Delarocque-Astagneau E, Semaille C, Larsen C. [HBs antigen screening: to be improved]. 69èmes Journées scientifiques de l'Association Française pour l'Etude du Foie (AFEF). Paris. 2011.

18. Brouard C, Leon L, Pioche C, Bousquet V, Semaille C, Larsen C. [Hepatitis B and C screening in France in 2010. The LaboHep 2010 Study]. Bull Epidemiol Hebd 2013,19:205-209.

19. Pioche C, Leon L, Larsen C, Lot F, Pillonel J, Brouard C. [Hepatitis B and C screening in France in 2013. The LaboHep 2013 Study]. Bull Epidémiol Hebd 2015,26-27:478-484.

20. Delarocque-Astagneau E, Meffre C, Dubois F, Pioche C, Le Strat Y, RoudotThoraval F, et al. The impact of the prevention programme of hepatitis C over more than a decade: the French experience. J Viral Hepat 2010,17:435-443.

21. Jauffret-Roustide M, Le Strat Y, Couturier E, Thierry D, Rondy M, Quaglia M, et al. A national cross-sectional study among drug-users in France: epidemiology of HCV and highlight on practical and statistical aspects of the design. BMC Infect Dis 2009,9:113.

22. Brouard C, Larsen C, Pioche C, Jauffret-Roustide M, Pillonel J, Velter A, et al. [Epidemiology of hepatitis B and hepatitis C - focus on screening] 86ème rencontre du Crips Île-de-France 2013.

23. Brouard C, Gautier A, Saboni L, Jestin C, Semaille C, Beltzer N. Hepatitis B knowledge, perceptions and practices in the French general population: the room for improvement. BMC Public Health 2013,13:576.

24. Vignier N, Jestin C, Arwidson P. Perceptions de l'hépatite B et de sa prévention. Premiers résultats d'une étude qualitative. BEH 2009:212.

25. Tosini S, Rioux C, Pelissier G, Bouvet E. Étude de perception des risques de l'hépatite virale $B$ et de sa prévention vaccinale dans une Consultation de dépistage anonyme et gratuit (CDAG) parisienne en 2007. Bull Epidemiol Hebd. 2009 2009,20-21:217-220.

26. Bottero J, Boyd A, Lemoine M, Carrat F, Gozlan J, Collignon A, et al. Current state of and needs for hepatitis B screening: results of a large screening study in a lowprevalent, metropolitan region. PLoS One 2014,9:e92266.

27. Gautier. A, C. J. [General practitionners practices for viral hepatitis screening in France in 2009] BEHWeb 2011,1.

28. Kowalik C. [Evaluation of the hepatitis $C$ screening in général medicine practice in the Annecy area in 2009]. Grenoble, France: Joseph Fourié University; 2009.

29. Livrozet JM, Py AM, Elghosi B, Bouée S, Aubert J, Rozenbaum W, et al. [Hepatitis C screening in general practice]. Rev Prat Médecine Générale 2005,19:895-899.

30. Haute Autorité de Santé (HAS). HIV infection screening in France - laboratory tests and algorithms. In: http://www.has-sante.fr/portail/jcms/c 866949/en/hivinfection-screening-in-france-screening-strategies?xtmc $=\& x t c r=2 ; 2008$.

31. Cazein F LSY, Dutil J, Couturier S, Ramus C, Semaille C,. [HIV infection screening in France, 2003-2012]. Bull Epidémiol Hebd. 2013,33-34:410-416.

32. Morlat P. [Management of people leaving with HIV. 2013 report: experts recommendations]. La documentation française 2013. 
33. British HIV Association (BHIVA). UK National Guidelines for HIV Testing 2008. In; 2008.

34. Shivkumar S, Peeling R, Jafari Y, Joseph L, Pai NP. Rapid point-of-care first-line screening tests for hepatitis B infection: a meta-analysis of diagnostic accuracy (1980-2010). Am J Gastroenterol 2012,107:1306-1313.

35. Shivkumar S, Peeling R, Jafari Y, Joseph L, Pant Pai N. Accuracy of rapid and pointof-care screening tests for hepatitis $\mathrm{C}$ : a systematic review and meta-analysis. Ann Intern Med 2012,157:558-566.

36. Bottero J, Boyd A, Gozlan J, Lemoine M, Carrat F, Collignon A, et al. Performance of rapid tests for detection of HBsAg and anti-HBsAb in a large cohort, France. J Hepatol 2013,58:473-478.

37. Chevaliez S, Poiteau L, Rosa I, Soulier A, Roudot-Thoraval F, Laperche S, et al. Prospective assessment of rapid diagnostic tests for the detection of antibodies to hepatitis C virus, a tool for improving access to care. Clin Microbiol Infect 2016.

38. Haute Autorité de Santé (HAS). [Use of rapid point-of-care first-line screening tests in hepatitis C screening strategy]. In. Saint Denis, France; 2014.

39. Morano JP, Zelenev A, Lombard A, Marcus R, Gibson BA, Altice FL. Strategies for hepatitis $\mathrm{C}$ testing and linkage to care for vulnerable populations: point-of-care and standard HCV testing in a mobile medical clinic.J Community Health 2014,39:922-934.

40. Stockman LJ, Guilfoye SM, Benoit AL, Vergeront JM, Davis JP. Rapid hepatitis C testing among persons at increased risk for infection--Wisconsin, 2012-2013. MMWR Morb Mortal Wkly Rep 2014,63:309-311.

41. Bottero J, Boyd A, Gozlan J, Carrat F, Nau J, Pauti MD, et al. Simultaneous Human Immunodeficiency Virus-Hepatitis B-Hepatitis C Point-of-Care Tests Improve Outcomes in Linkage-to-Care: Results of a Randomized Control Trial in Persons Without Healthcare Coverage. Open Forum Infect Dis 2015,2:ofv162.

42. Brouard C, Le Strat Y, Pillonel J, Larsen C, Semaille C. Characteristics of undiagnosed HBV or HCV chronically infected population in France: a need for reconsidering testing strategies (abstract 088). Journal of Hepatology 2014,60:S36.

43. Supervie V, Ndawinz JD, Lodi S, Costagliola D. The undiagnosed HIV epidemic in France and its implications for HIV screening strategies. AIDS 2014,28:17971804.

44. Benova L, Mohamoud YA, Calvert C, Abu-Raddad LJ. Vertical transmission of hepatitis $C$ virus: systematic review and meta-analysis. Clin Infect Dis 2014,59:765-773.

45. Cousien A, Tran VC, Deuffic-Burban S, Jauffret-Roustide M, Dhersin JS, Yazdanpanah Y. Hepatitis c treatment as prevention of viral transmission and liver-related morbidity in persons who inject drugs. Hepatology 2015.

46. Bottero J, Boyd A, Gozlan J, Carrat F, Lemoine M, Rougier H, et al. Effectiveness of Hepatitis B rapid tests towards linkage to care: results of a randomized, multicenter study. European Journal of Gastroenterology \& Hepatology 2016. 


\section{Tables}

Table 1 : Questions to guide the implementation of a status report on hepatitis B and C screening and the development of subsequent recommendations [11]

- What are the current screening recommendations?

- What are the epidemiological data enabling to assess the screening effectiveness and guiding the development of new recommendations?

- Who are the screening actors and what are their tools?

- What are the screening barriers and leverages?

- Should screening strategies and players change with the availability of more effective treatments and of new tools?

- General population-based screening

- Screening for birth cohorts

- Targeted repeated screening

- Community-based screening

- Should screening strategies for HCV, HBV be combined with HIV screening ? If so, how? 
Table 2 : French guidelines for HBV and HCV screening, before 2014 [12, 14]

\section{2. a. HBV}

- People born or who have lived in countries with an HBV endemic level either high (Sub-Saharan Africa, Asia) or medium (DOM-TOM, Eastern and Southern Europe, North Africa, Middle East, Indian Subcontinent and South America);

- The household and sexual partners of HBV-carrier subject;

- Users of intravenous or intranasal drug;

- Patients who may have received massive or iterative blood transfusions;

- Travelers in a country with high or medium HBV endemicity;

- Adults and children attending psychiatric institutions;

- Persons with tattoos or body piercing;

- Prisoners and previously incarcerated persons;

- People who have sex with different partners;

- People with occupational exposure;

- Persons with a positive serology for HIV or HCV, or having a current or recent sexually transmitted infection.

\section{2.b. HCV [12] :}

- Persons who have received blood products or tissue transplant, cells or organs, before 1992;

- Persons who injected drugs at least once in their lives;

- Persons exposed to nosocomial invasive procedures before 1997;

- Patients undergoing hemodialysis;

- Children born to HCV-positive mother;

- Persons with positive serology for HIV;

- Sexual partners and members of the household of subjects infected with HCV;

- Prisoners and previously incarcerated persons; 
- People from or who received care in countries with a high HCV endemicity (Southeast Asia, Middle East, Africa, South America);

- Persons who have had tattoos, body piercing, acupuncture or mesotherapy procedures without the use of disposable or personal equipment

- Persons with elevated ALT blood levels of unknown etiology. 


\section{Figures :}

Figure 1 : Estimated prevalence of HCV RNA and HBs antigen among the general population of metropolitan France in 2004, according to age and gender [9]
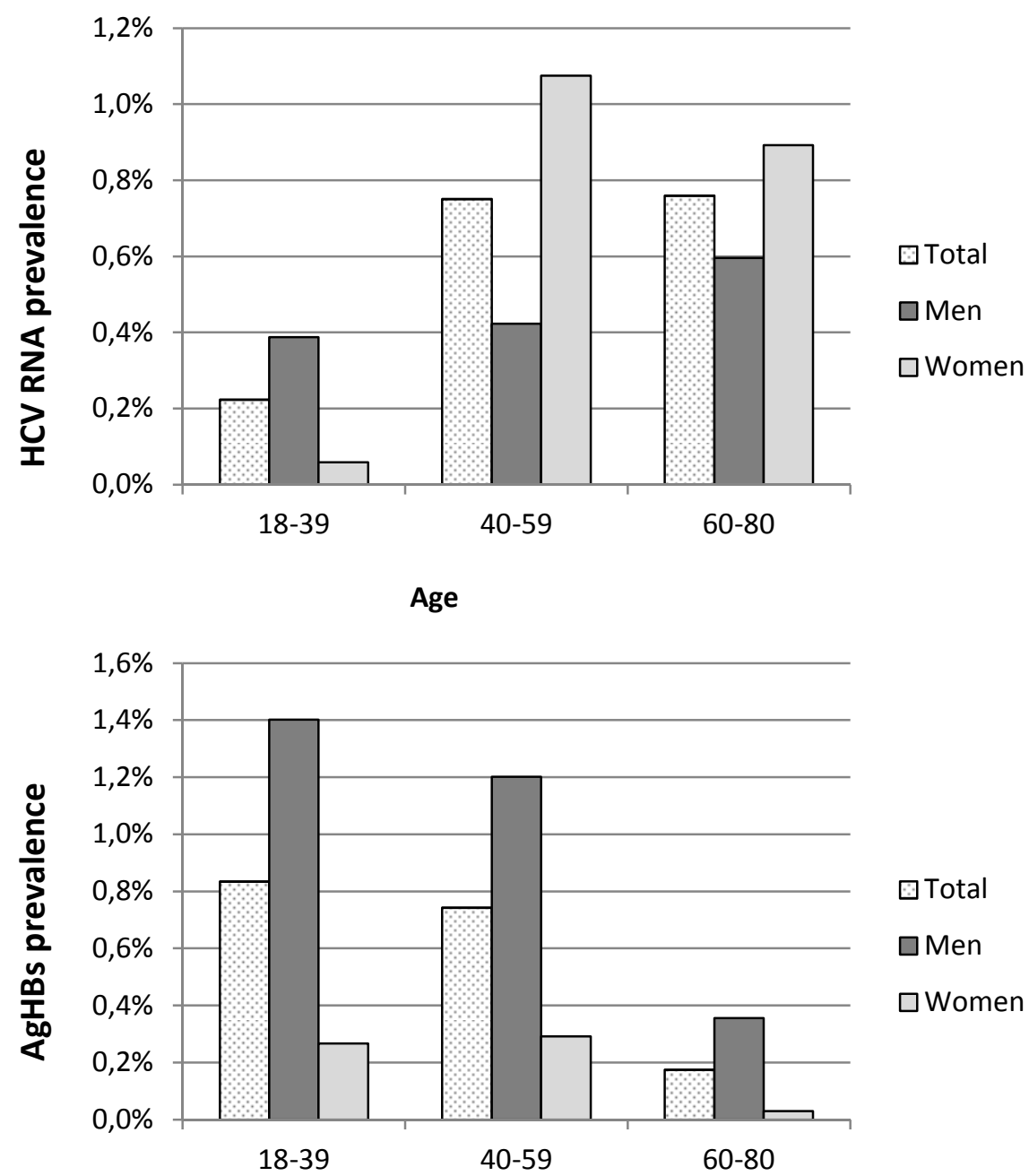

Age 
Figure 2: Estimated rate of people with chronic HCV or HBV and aware of their viral status among the French metropolitan general population in 2004, according to age [9]

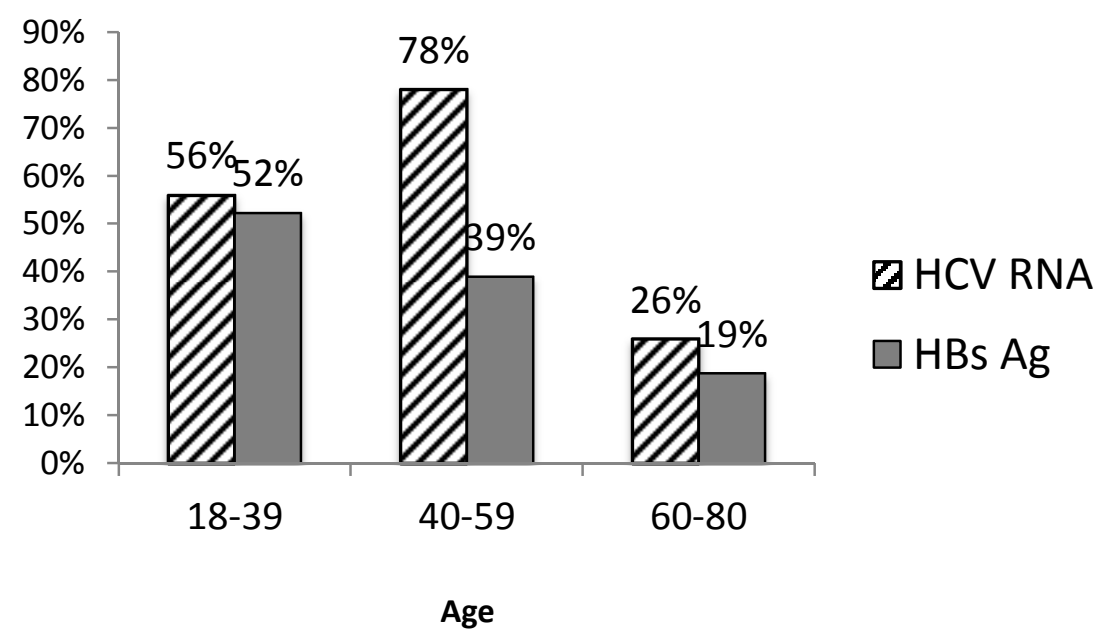


Figure 3: Distribution by age and gender of undiagnosed people for chronic HCV or HBV among the French metropolitan general population in 2004 [42]

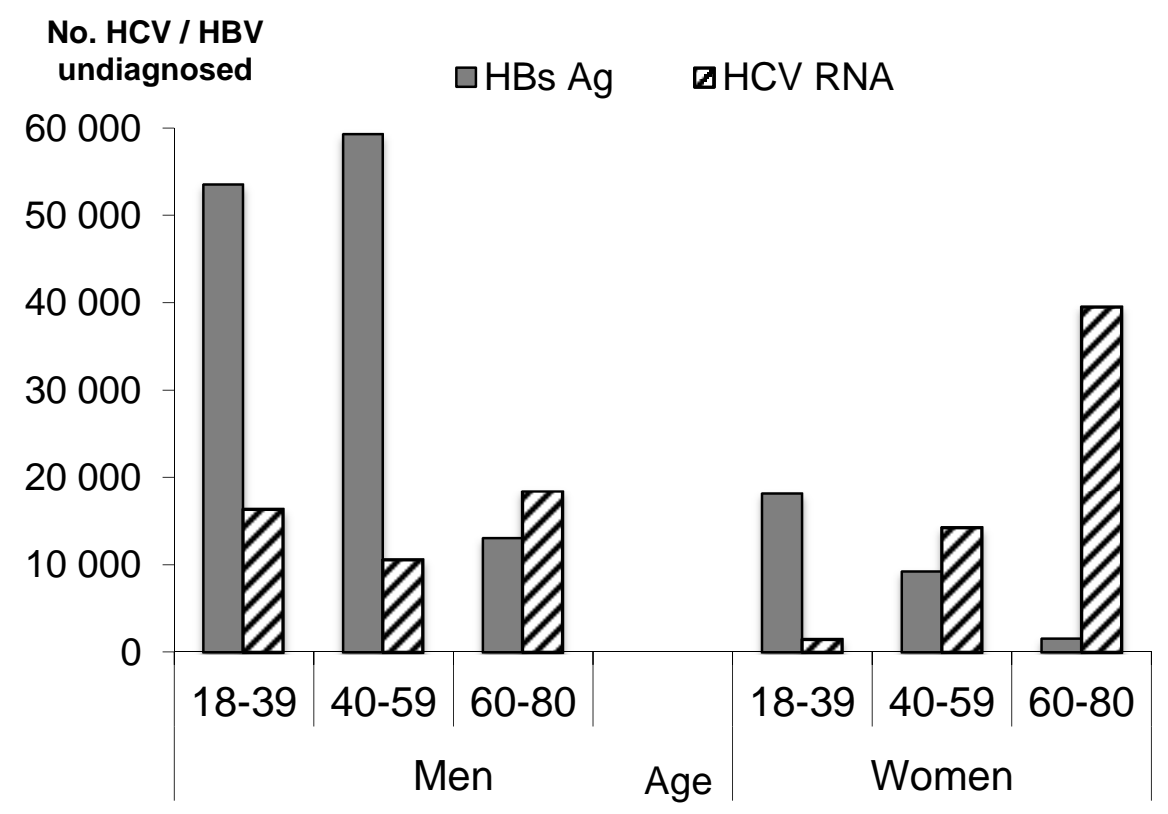

